\title{
Chitosan-based nanoparticles with damnacanthal suppress CRM1 expression
}

\author{
NADDA CHAICHANASAK ${ }^{1,2}$, PLEUMCHITT ROJANAPANTHU ${ }^{3}$, YONGDAE YOON ${ }^{1}$, \\ WANDEE GRITSANAPAN ${ }^{4}$, SUWABUN CHIRACHANCHAI ${ }^{5}$, KORBTHAM SATHIRAKUL $^{3}$, \\ THARARAT NUALSANIT ${ }^{6}$, JE KYUNG SEONG ${ }^{1}$ and SEUNG JOON BAEK ${ }^{1}$
}

${ }^{1}$ Department of Veterinary Medicine, College of Veterinary Medicine and Research Institute for Veterinary Science, Seoul National University, Seoul 08826, Republic of Korea; ${ }^{2}$ Department of Pharmacy, Faculty of Pharmacy, Mahidol University, Bangkok 10400; ${ }^{3}$ Drug Discovery and Development Center, Thammasat University, Rangsit, Pathumthani 12121; ${ }^{4}$ Phyto Product Research, Bangkok 10800; ${ }^{5}$ The Petroleum and Petrochemical College, Chulalongkorn University, Bangkok 10330; ${ }^{6}$ Chulabhorn International College of Medicine, Thammasat University, Rangsit, Pathumthani 12121, Thailand

Received April 27, 2018; Accepted August 8, 2018

DOI: $10.3892 / \mathrm{ol} .2018 .9507$

\begin{abstract}
Cancer is one of the leading causes of mortality worldwide. Phytochemicals may be promising anticancer agents given their various chemical structures and diverse biological activities. Damnacanthal (DAM) is a major bioactive component of Noni, which has been investigated previously as a cancer-preventive or chemotherapeutic agent. DAM has also been reported to exhibit anti-proliferative activity in several cancer types. In the present study, it was identified that DAM downregulates chromosome maintenance protein 1 (CRM1) expression in human cancer cells. The application of chitosan-based nanoparticles (NPs) with DAM also induced CRM1 downregulation, which suggests that chitosan-based NPs may be effective vehicles for delivery of phytochemicals such as DAM. It was also identified that DAM increased the levels of the tumor suppressor non-steroidal anti-inflammatory drugs-activated gene 1 in the nucleus, thereby leading to enhanced anticancer effects. The results of the present study indicate that DAM and its nanoformulation may be a candidate anticancer drug.
\end{abstract}

Correspondence to: Dr Seung Joon Baek, Department of Veterinary Medicine, College of Veterinary Medicine and Research Institute for Veterinary Science, Seoul National University, 1 Gwanak, Gwana, Seoul 08826, Republic of Korea

E-mail: baeksj@snu.ac.kr

Abbreviations: DAM, damnacanthal; DAM-NPs, DAM nanoparticles; CRM1, chromosome maintenance protein 1

Key words: damnacanthal, chromosome maintenance protein 1, nanoparticles, chitosan, non-steroidal anti-inflammatory drugsactivated gene

\section{Introduction}

Cancer is one of the most common causes of mortality worldwide. Although various therapies for cancer have been developed, further research is required to decrease the mortality caused by cancer.

Phytochemicals are present in dietary plant-based products, and several phytochemicals have been identified to inhibit tumorigenesis in experimental animals and/or in vitro assays (1). Therefore, chemoprevention using phytochemicals may be a way to decrease cancer-associated mortality. The phytochemical damnacanthal (3-hydroxy-1-methoxyanthraquinone-2-aldehyde; DAM) is an anthraquinone compound, primarily present in plants of the Rubiaceae family. It has been reported to have anticancer and cancer-preventive activities, acting via various molecular targets, including induction of non-steroidal anti-inflammatory drugs-activated gene 1 (NAG-1) expression (2), cyclin D1 downregulation (3), activation of p38 mitogen-activated protein kinase signaling pathway (4) and inhibition of tyrosine kinase (5-7).

Chitosan, a cationic natural polysaccharide present in the exoskeleton of crustaceans, has been widely used as a drug delivery system. The advantages of using chitosan in nanoparticles (NPs) are its biocompatibility, biodegradability, non-toxicity, non-immunogenicity and abundance of functional groups. Encapsulation of DAM improved the mode of action of the NPs and decreased their toxicity, indicating that there may be multiple potential applications of phytochemical delivery by chitosan (8).

One of the key proteins that regulates tumor suppressors in cancer cells is the chromosome maintenance protein 1 (CRM1, also known as exportin 1), which serves a pivotal function in tumorigenesis (9) and may be a target for anticancer drugs. CRM1 is a nuclear export receptor involved in the export of large macromolecules including RNA and protein from the nuclear membrane to the cytoplasm. Excessive nuclear export may be one of the factors contributing to resistance to 
chemotherapy and cancer development (10). It has been identified that CRM1 is highly expressed in cancer, and a number of nuclear tumor suppressor proteins, including p53, p21 and NAG-1 $(11,12)$, are translocated to the cytoplasm and are degraded. Overexpression of CRM1 has been associated with poor prognosis in patients with several types of cancer (13). Thus, CRM1 may be considered a promising therapeutic target for anticancer drug development.

The aims of the present study were to evaluate the effect of DAM and its nanoformulation on CRM1 expression and to elucidate the underlying molecular mechanisms of DAM-mediated anticancer activity.

\section{Materials and methods}

Materials. DAM was isolated from the roots of Morinda citrifolia and was purified as described previously (14). Chitosan with $90 \%$ deacetylation $\left(M_{\mathrm{v}}, 150,000\right)$ was purchased from Seafresh Chitosan (Lab) Co. Ltd. (Chumphon, Thailand). Cancer cell lines were purchased from the American Type Culture Collection (Manassas, VA, USA). HCT-116 and U2OS cells were cultured in McCoy's 5A medium (Welgene Inc., Gyeongsan, Korea) supplemented with $10 \%$ fetal bovine serum (Hyclone; GE Healthcare Life Sciences, Logan UT, USA), $100 \mu \mathrm{g} / \mathrm{ml}$ penicillin and $100 \mu \mathrm{g} / \mathrm{ml}$ streptomycin. The cells were incubated at $37^{\circ} \mathrm{C}$ under a humidified atmosphere containing $5 \% \mathrm{CO}_{2}$. Antibodies were purchased from Santa Cruz Biotechnology, Inc. (Dallas, TX, USA), except for the anti-NAG-1 antibody, which was obtained as previously described (15).

Preparation of DAM-NPs. DAM-NPs were prepared using deoxycholic and poly(ethylene glycol) methyl ether-grafted chitosan as a drug carrier. DAM was incorporated into the NPs using the dialysis method described previously (8). Briefly, the polymer was dissolved in water and mixed with DAM solution in dimethyl sulfoxide (DMSO). The mixture was ultrasonicated and dialyzed in $0.9 \% \mathrm{NaCl}$ at $4^{\circ} \mathrm{C}$. DAM-NPs were freeze-dried for further use.

Cell proliferation assay. The effect of DAM and DAM-NPs on the proliferation of HCT-116 and U2OS cells was investigated using the CellTiter 96 Aqueous One Solution Cell Proliferation Assay (Promega Corporation, Madison, WI, USA). The cells were seeded at a concentration of 3,000 cells/well in 96-well tissue culture plates. The cells were then treated with 1 or $10 \mu \mathrm{M}$ DAM or DMSO as a control, and DAM-NPs (equivalent concentration of $50 \mu \mathrm{M}$ DAM) or DAM-free NPs as controls. At 0,1 and 3 days after treatment (for DAM-NPs and NPs) or 0,1 and 4 days after treatment (for DAM and DMSO), $20 \mu$ l CellTiter 96 Aqueous One Solution was added to each well. The plate was then incubated at $37^{\circ} \mathrm{C}$ for $1 \mathrm{~h}$. The absorbance at $490 \mathrm{~nm}$ was determined using an iMARK ${ }^{\text {TM }}$ microplate absorbance reader (Bio-Rad Laboratories, Inc., Hercules, CA, USA).

Apoptosis assay. Apoptotic cells were detected using the Annexin V-Fluorescein Isothiocyanate Apoptosis Detection kit (BioVision, Inc., Milpitas, CA, USA). Briefly, cells were plated in 6-well culture dishes and treated with vehicle,
DAM, NPs and DAM-NPs followed by incubation at $37^{\circ} \mathrm{C}$ for $24 \mathrm{~h}$. Samples were prepared according to the manufacturer's protocol. Apoptosis was detected using a Cell $\mathrm{Lab}^{\mathrm{TM}}$ Quanta SC flow cytometer (Beckman Coulter, Inc., Brea, CA, USA) with excitation and emission settings of 488 and $530 \mathrm{~nm}$, respectively. The images were captured with a Quanta SC flow cytometer (Beckman Coulter, Inc.) and processed with Flowing Software 2.5.1 (University of Turku, Turku, Finland).

Reverse transcription-semi-quantitative polymerase chain reaction (RT-PCR). HCT-116 and U2OS cells were grown to between 80 and $90 \%$ confluence in a $6-\mathrm{cm}$ plate followed by treatment with $50 \mu \mathrm{M}$ DAM or DAM-NPs (equivalent concentration of $50 \mu \mathrm{M}$ DAM), and DMSO or NPs as vehicle controls. After $24 \mathrm{~h}$, total RNA was extracted using TRIzol ${ }^{\circledR} \mathrm{LS}$ reagent (Invitrogen; Thermo Fisher Scientific, Inc., Waltham, MA, USA) and then reverse-transcribed into cDNA using a Verso cDNA synthesis kit (Thermo Fisher Scientific, Inc.), according to the manufacturer's protocol. PCR was performed for 30 cycles of $94^{\circ} \mathrm{C}$ for $30 \mathrm{sec}, 60^{\circ} \mathrm{C}$ for $30 \mathrm{sec}$ and $72^{\circ} \mathrm{C}$ for 1 min with specific primers for human (h)CRM1 and hGAPDH (hCRM1 forward, 5'-AATGTGAGAGCCTGCAAAGC-3'; hCRM1 reverse, 5'-CGGCTCACCCAACCAGATAT-3'; hGAPDH forward, 5'-GACCACAGTCCATGCCATCACT-3'; hGAPDH reverse, 5'-TCCACCCTGTTGCTGTAG-3'). Each PCR product was electrophoresed on a $1.4 \%$ agarose gel with NEOgreen (NeoScience, Co., Ltd., Suwon, Korea) staining. Each value was normalized to the expression of hGAPDH.

Western blot analysis. HCT-116 and U2OS cells were grown to between 80 and $90 \%$ confluence in a $6-\mathrm{cm}$ plate and treated with $50 \mu \mathrm{M}$ DAM or DAM-NPs (equivalent concentration of $50 \mu \mathrm{M}$ DAM), and DMSO or NPs as vehicle controls. Total cell lysates were isolated using radioimmunoprecipitation assay cell lysis buffer $(1 \mathrm{X})$ with EDTA supplemented with protease inhibitor $(0.5 \mathrm{mM}$ phenylmethylsulfonyl fluoride) and phosphatase inhibitor $\left(1 \mathrm{mM} \mathrm{Na} \mathrm{VO}_{4}\right)$. Nuclear and cytoplasmic extracts were purified by using NE-PER Nuclear and Cytoplasmic Extraction Reagents (Thermo Fisher Scientific, Inc.) according to the manufacturer's protocol. Protein concentration was determined by the bicinchoninic acid protein assay (Pierce; Thermo Fisher Scientific, Inc.) using bovine serum albumin (Pierce; Thermo Fisher Scientific, Inc.) as the standard. 10\% SDS-PAGE was used to separate 60 or $30 \mu \mathrm{g}$ of proteins from the cell lysates. These proteins were then transferred onto a nitrocellulose membrane. The blot was blocked with $5 \%$ skimmed milk in Tris-buffered saline (TBS) containing $0.1 \%$ Tween-20 (TBS-T), applied overnight. The membranes were incubated at room temperature with primary antibodies against NAG-1, CRM1 (sc-74454), $\beta$-actin (sc-47778), $\alpha$-tubulin (sc-398103) and lamin A/C (sc-376248), diluted in 5\% skimmed milk in TBS-T solution $(1: 1,000)$ for $1 \mathrm{~h}$. Following washing with TBS-T four times, the membrane was incubated with horseradish peroxidase (HRP)-conjugated goat anti-rabbit (Thermo Fisher Scientific, Inc.; cat. no. 31460) or HRP-conjugated goat anti-mouse (Invitrogen; Thermo Fisher Scientific, Inc.; cat. no. 62-6520) for $1 \mathrm{~h}$ and washed with TBS-T six times. The proteins were detected by chemiluminescence using Enhanced Chemiluminescence Western 
A

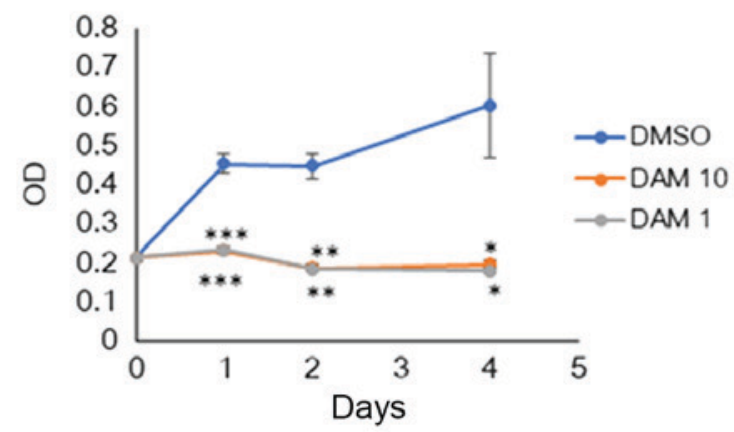

C

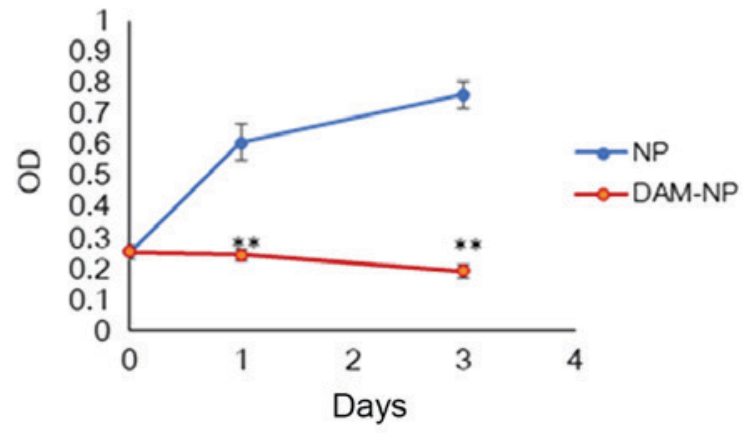

B

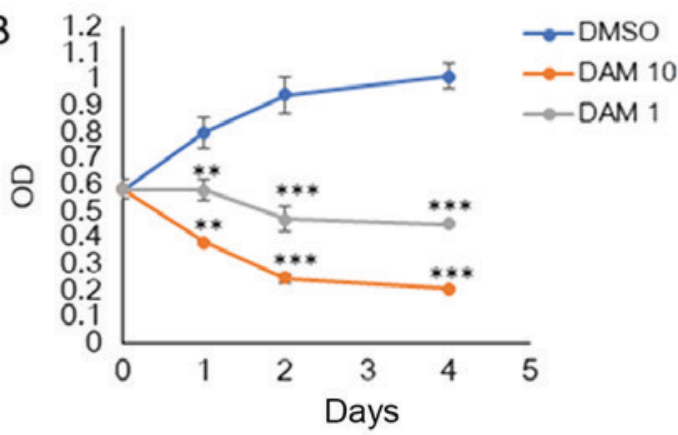

D

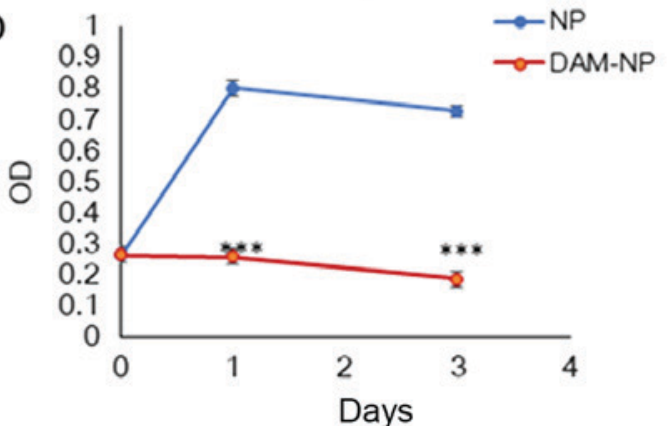

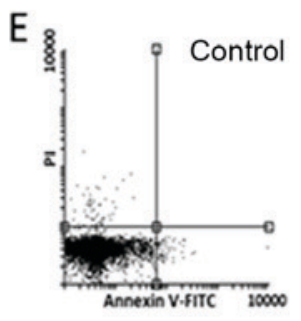
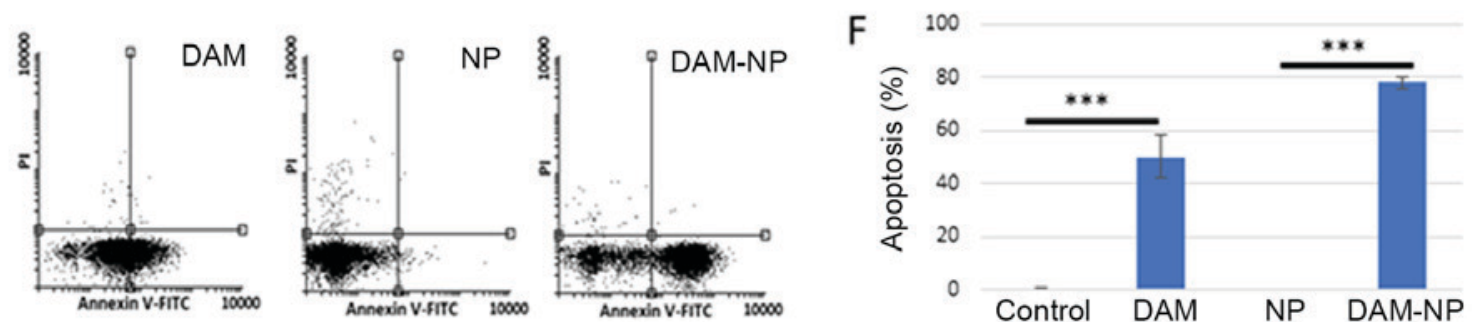

Figure 1. Effect of DAM and DAM-NPs on HCT-116 and U2OS cell proliferation. (A) HCT-116 and (B) U2OS cells were treated with DAM or DMSO for 4 days, and (C) HCT-116 and (D) U2OS cells were also treated with NPs or DAM-NPs (50 $\mu \mathrm{M}$ final DAM concentration) for 3 days. Results are expressed as the mean \pm standard deviation of four independent experiments. ${ }^{*} \mathrm{P}<0.05,{ }^{* * *} \mathrm{P}<0.01,{ }^{* * * *} \mathrm{P}<0.001$ vs. DMSO or NP-treated cells. U2OS cells were plated at $1 \times 10^{6}$ cells/well in 6-well plates, incubated with vehicle or $50 \mu \mathrm{M}$ DAM or DAM-NPs for $24 \mathrm{~h}$ and analyzed for apoptosis. (E) Representative flow cytometric profiles. (F) Early apoptosis rate (Annexin V-positive and PI-negative). Results are expressed as the mean \pm standard deviation of three independent experiments. ${ }^{* * *} \mathrm{P}<0.001$ vs. DMSO-treated cells. DAM, damnacanthal; DAM-NPs, DAM nanoparticles; DMSO, dimethyl sulfoxide; PI, propidium iodide; FITC, fluorescein isothiocyanate; NPs, nanoparticles; OD, optical density.

Blotting Detection Reagent (GE Healthcare, Little Chalfont, UK) and visualized using MicroChemi (software 4.2; DNR Bio-Imaging Systems, Ltd., Neve Yamin, Israel).

Statistics. Statistical analysis was performed with SSPS software (version 25; SPSS, Chicago, IL, USA). Statistical significance was determined by analysis of variance and Scheffe's test. $\mathrm{P}<0.05$ was considered to indicate a statistically significant difference. Results are expressed as the mean \pm standard deviation.

\section{Results}

$D A M-N P$ s inhibit cell proliferation. It has been identified previously that treatment with DAM inhibits cancer cell proliferation (2). In the present study, the anti-proliferative effect of DAM and DAM-NPs on human colorectal and osteosarcoma cancer cells, HCT-116 and U2OS, respectively, was identified. The two cell lines, which each express wild-type p53, were used in this assay because it is known that DAM induces p53 expression and its induction leads to cell proliferation inhibition in cancer cells (16). The cells were treated with 1 or $10 \mu \mathrm{M}$ DAM for 1,2 and 4 days. The cells were also treated with DAM-NPs at the equivalent DAM concentration $(50 \mu \mathrm{M})$ for 1 and 3 days. The results indicated that DAM and DAM-NPs significantly decreased the proliferation of HCT-116 ( $\mathrm{P}<0.001$ and $\mathrm{P}<0.01$, respectively) and U2OS $(\mathrm{P}<0.01$ and $\mathrm{P}<0.001$, respectively) cells after 1 day of treatment, compared with control cell proliferation (Fig. 1A-D). Furthermore, cell proliferation continuously decreased after 4 days of treatment. It was also identified that cell proliferation arrest by DAM and DAM-NPs resulted from induction of early apoptosis, as assessed using an Annexin V assay (Fig. 1E and F). These results indicated that DAM-NPs exhibit a similar activity to that of DAM in that they inhibit the proliferation of cancerous cells (2).

DAM and DAM-NPs inhibit CRM1 expression. To investigate the effect of DAM and DAM-NPs on CRM1 expression, HCT-116 and U2OS cells were treated with $50 \mu \mathrm{M}$ DAM and DAM-NPs at the equivalent DAM concentration $(50 \mu \mathrm{M})$. Western blots from total cell lysates with $60 \mu \mathrm{g}$ protein were performed to determine CRM1 expression. As presented in Fig. 2, CRM1 was downregulated in HCT-116 and U2OS 
A

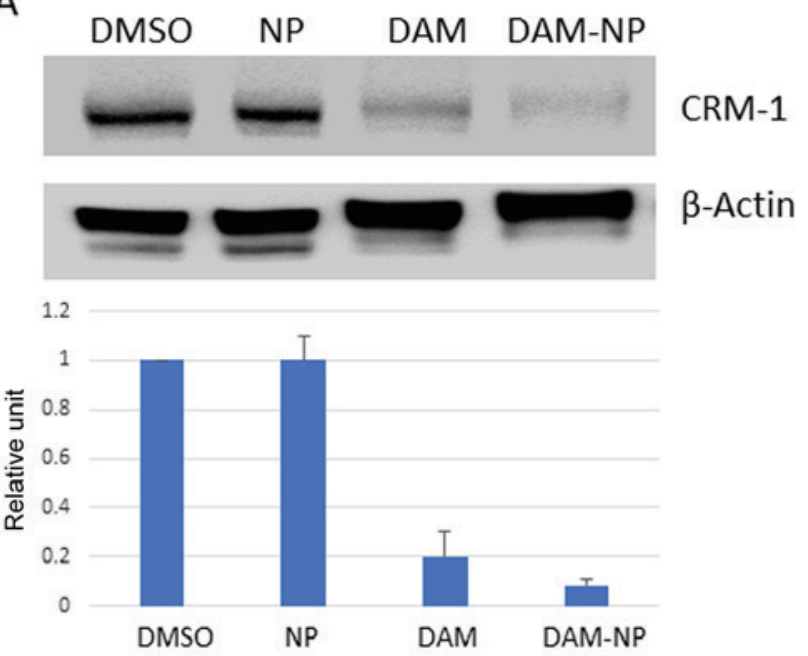

B

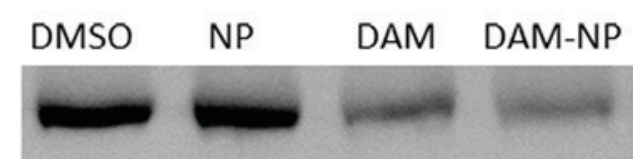

CRM-1

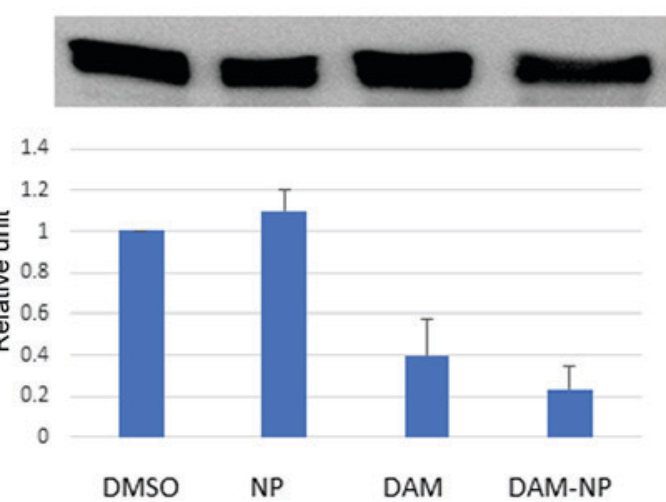

Figure 2. Effect of DAM and DAM-NPs on CRM1 expression. (A) HCT-116 and (B) U2OS cells were treated with control (0.1\% DMSO or NPs), DAM (50 $\mu$ M) or DAM-NPs (50 $\mu \mathrm{M}$ final DAM concentration) for $24 \mathrm{~h}$. Cell lysates were subjected to western blot analysis using anti-CRM1 and anti- $\beta$-actin antibodies Results are representative of three independent experiments. Densitometry results are expressed as fold induction relative to vehicle-treated cells normalized to $\beta$-actin. DAM, damnacanthal; DAM-NPs, DAM nanoparticles; DMSO, dimethyl sulfoxide; CRM1, chromosome maintenance protein 1; NPs, nanoparticles .

A
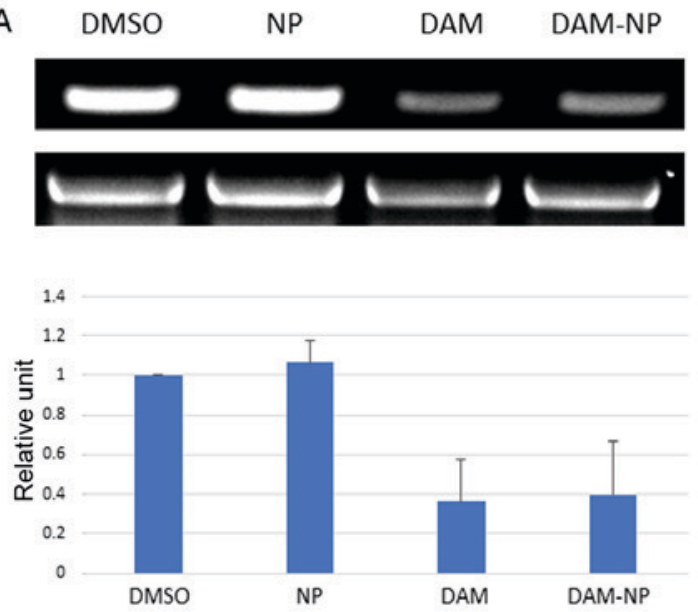

B DMSO NP DAM DAM-NP hCRM1 hGAPDH

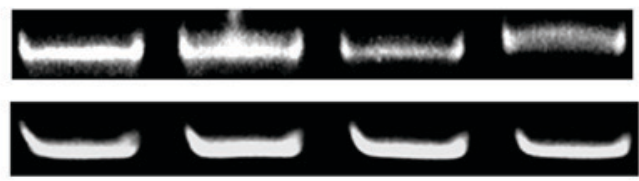

hCRM1 hGAPDH

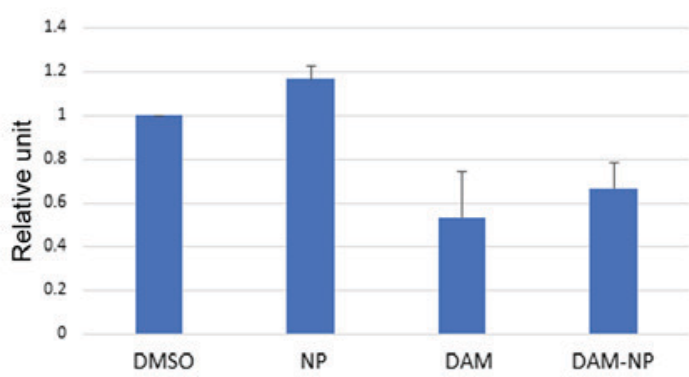

Figure 3. (A) HCT-116 and (B) U2OS cells were treated with control (0.1\% DMSO or NPs), DAM (50 $\mu \mathrm{M})$ or DAM-NPs (50 $\mu \mathrm{M}$ of final DAM concentration) for $24 \mathrm{~h}$. hCRM1 mRNA levels were quantified using the reverse transcription-semi-quantitative polymerase chain reaction. Results are representative of three independent experiments. Densitometry results are expressed as fold induction relative to vehicle-treated cells adjusted to hGAPDH. DAM, damnacanthal; DAM-NPs, DAM nanoparticles; DMSO, dimethyl sulfoxide; NPs, nanoparticles; hCRM1, human chromosome maintenance protein 1; hGAPDH, human GAPDH.

cells treated with DAM and DAM-NPs compared with that in control cells. This result indicated that DAM and DMA-NPs decrease CRM1 expression at the protein level. To further verify the CRM1 downregulation at the transcriptional level, mRNA expression from HCT-116 and U2OS cells following treatment with DAM and DAM-NPs for $24 \mathrm{~h}$ was analyzed. As presented in Fig. 3A and B, the level of CRM1 mRNA decreased in the two cell lines following treatment. These results indicated that DAM and DAM-NPs also downregulate CRM1 expression at the transcriptional level.

CRM1 downregulation results in the accumulation of NAG-1. It has been identified that NAG-1 is a tumor suppressor protein translocated from the nucleus to the cytoplasm by CRM1 (12). To confirm that the decrease in CRM1 expression led to the nuclear accumulation of NAG-1, western blot analyses for NAG-1 in nuclear as well as in cytoplasmic extracts were performed. As presented in Fig. 4, an increase in the NAG-1 level in the nuclear fraction was observed in DAM- and DAM-NP-treated cells. This may have resulted from the inhibition of CRM1 and may be mediated by DAM or DAM-NPs.

\section{Discussion}

Cancer is the primary cause of mortality in Thailand, and the second most common cause of mortality worldwide $(17,18)$. In the last few decades, potential therapeutics for cancer have been investigated in a number of ways; however, extensive efforts are required to decrease the incidence of cancer and associated mortality. It has been indicated that plant phytochemicals serve an important function in anti-carcinogenesis (1). DAM, 


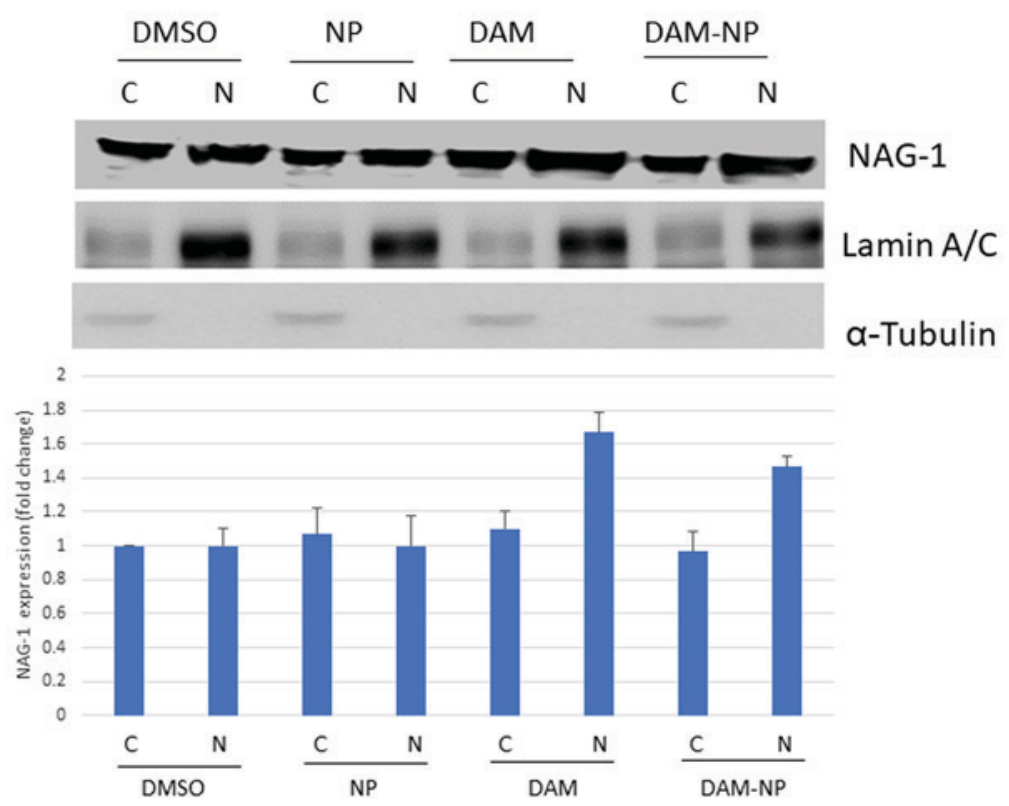

Figure 4. DAM and DAM-NPs increase NAG-1 expression in the nucleus of HCT-116 cells. HCT-116 cells were treated with control (0.1\% DMSO or NPs), DAM $(50 \mu \mathrm{M})$ or DAM-NPs (50 $\mu \mathrm{M}$ final DAM concentration) for $24 \mathrm{~h}$. Nuclear and cytoplasmic extracts were subjected to western blot analysis using anti-NAG-1, anti-lamin A/C and anti- $\alpha$-tubulin antibodies. Results are representative of three independent experiments. The densitometry represents NAG-1 fold induction, compared with DMSO-treated cytoplasmic NAG-1 expression. NAG-1, non-steroidal anti-inflammatory drugs-activated gene 1; DAM, damnacanthal; DAM-NPs, DAM nanoparticles; DMSO, dimethyl sulfoxide; NPs, nanoparticles; C, cytoplasmic; N, nuclear.

extracted from M. citrifolia, commonly called noni (19), has potential anticancer effects. In the present study, it was identified that DAM inhibits the proliferation of HCT-116 and U2OS cells. DAM and encapsulated DAM inhibited CRM1 expression in the two cell lines, which may be key to its anticancer activity.

CRM1 is an export protein that facilitates the transport of large molecules including tumor suppressor proteins from the nucleus to the cytoplasm (20). Previous studies have identified that CRM1 overexpression occurs in various types of cancer such as osteosarcoma, ovarian cancer, pancreatic cancer, glioma, cervical cancer and renal cell carcinoma (21-26), making CRM1 a focal target for anticancer drugs. In the present study, it was identified that DAM and DAM-NPs downregulate CRM1 expression in HCT-116 and U2OS cells. This result was corroborated by analyzing the expression of NAG-1 protein in the nucleus and cytoplasm. Following treatment with DAM and DAM-NPs, NAG-1 expression was increased in the nucleus compared with in the cytoplasm. This may be a consequence of CRM1 downregulation and the associated decrease in NAG-1 transportation from the nucleus to the cytoplasm. CRM1 is highly expressed in several types of cancer, and its inhibition is beneficial. Although it requires further investigation, DAM may affect CRM1 activity by directly binding to CRM1, similar to leptomycin B (a synthetic CRM1 inhibitor). These results are of importance because DAM is a natural compound, which is associated with fewer side effects compared with synthetic CRM1 inhibitors and may be used to develop potent anticancer drugs.

\section{Acknowledgements}

The authors would like to thank Mr Hyun Jik Lee from Seoul National University (Seoul, Korea) for his technical support in the present study.

\section{Funding}

The present study was supported by the Research Resettlement Fund for the new faculty, the Research Institute for Veterinary Science, and BK21 PLUS Program for Creative Veterinary Science Research Center, Seoul National University, and by a National Research Foundation of Korea grant funded by the Korea government (2018R1A2B2002923). The present study was also supported by the Royal Golden Jubilee PhD Program (PHD/0235/2549), Thailand.

\section{Availability of data and materials}

The datasets used and/or analyzed during the current study are available from the corresponding author on reasonable request.

\section{Authors' contributions}

NC, PR, KS and SJB designed and conceived the present study. $\mathrm{NC}, \mathrm{YY}$ and TN performed the experiments. NC and SJB wrote the manuscript. WG, SC, JKS and SJB analyzed the data.

\section{Ethics approval and consent to participate}

Not applicable.

\section{Patient consent for publication}

Not applicable.

\section{Competing interests}

All authors declare that they have no competing interests. 


\section{References}

1. Wenzel U, Kuntz S, Brendel MD and Daniel H: Dietary flavone is a potent apoptosis inducer in human colon carcinoma cells. Cancer Res 60: 3823-3831, 2000.

2. Nualsanit T, Rojanapanthu P, Gritsanapan W, Lee SH, Lawson D and Baek SJ: Damnacanthal, a noni component, exhibits antitumorigenic activity in human colorectal cancer cells. J Nutr Biochem 23: 915-923, 2012.

3. Sukamporn P, Rojanapanthu P, Silva G, Zhang X, Gritsanapan W and Baek SJ: Damnacanthal and its nanoformulation exhibit anti-cancer activity via cyclin D1 down-regulation. Life Sci 152: 60-66, 2016.

4. Lin FL, Hsu JL, Chou CH, Wu WJ, Chang CI and Liu HJ: Activation of p38 MAPK by damnacanthal mediates apoptosis in SKHep 1 cells through the DR5/TRAIL and TNFR1/TNF- $\alpha$ and p53 pathways. Eur J Pharmacol 650: 120-129, 2011.

5. Faltynek CR, Schroeder J, Mauvais P, Miller D, Wang S, Murphy D, Lehr R, Kelley M, Maycock A, Michne W, et al: Damnacanthal is a highly potent, selective inhibitor of p56lck tyrosine kinase activity. Biochemistry 34: 12404-12410, 1995.

6. Garcia-Vilas JA, Quesada AR and Medina MA: Damnacanthal, a noni anthraquinone, inhibits c-Met and is a potent antitumor compound against Hep G2 human hepatocellular carcinoma cells. Sci Rep 5: 8021, 2015.

7. Ohashi K, Sampei K, Nakagawa M, Uchiumi N, Amanuma T, Aiba S, Oikawa M and Mizuno K: Damnacanthal, an effective inhibitor of LIM-kinase, inhibits cell migration and invasion. Mol Biol Cell 25: 828-840, 2014.

8. Sukamporn P, Baek SJ, Gritsanapan W, Chirachanchai S, Nualsanit $\mathrm{T}$ and Rojanapanthu P: Self-assembled nanomicelles of damnacanthal-loaded amphiphilic modified chitosan: Preparation, characterization and cytotoxicity study. Mater Sci Eng C Mater Biol Appl 77: 1068-1077, 2017.

9. Kanai M, Hanashiro K, Kim SH, Hanai S, Boulares AH, Miwa $\mathrm{M}$ and Fukasawa K: Inhibition of Crm1-p53 interaction and nuclear export of p53 by poly(ADP-ribosyl)ation. Nat Cell Biol 9: 1175-1183, 2007.

10. El-Tanani M, Dakir el-H, Raynor B and Morgan R: Mechanisms of nuclear export in cancer and resistance to chemotherapy. Cancers (Basel) 8: pii: E35, 2016.

11. Gravina GL, Senapedis W, McCauley D, Baloglu E, Shacham S and Festuccia C: Nucleo-cytoplasmic transport as a therapeutic target of cancer. J Hematol Oncol 7: 85, 2014.

12. Min KW, Liggett JL, Silva G, Wu WW, Wang R, Shen RF, Eling TE and Baek SJ: NAG-1/GDF15 accumulates in the nucleus and modulates transcriptional regulation of the Smad pathway. Oncogene 35: 377-388, 2016.

13. Sun Q, Chen X, Zhou Q, Burstein E, Yang S and Jia D: Inhibiting cancer cell hallmark features through nuclear export inhibition. Signal Transduct Target Ther 1: 16010, 2016.

14. Nualsanit T, Rojanapanthu P, Gritsanapan W, Kwankitpraniti T, Min KW and Baek SJ: Damnacanthal-induced anti-inflammation is associated with inhibition of NF- $\kappa \mathrm{B}$ activity. Inflamm Allergy Drug Targets 10: 455-463, 2011.
15. Baek SJ, Okazaki R, Lee SH, Martinez J, Kim JS, Yamaguchi K, Mishina Y, Martin DW, Shoieb A, McEntee MF and Eling TE: Nonsteroidal anti-inflammatory drug-activated gene-1 over expression in transgenic mice suppresses intestinal neoplasia. Gastroenterology 131: 1553-1560, 2006.

16. Aziz MY, Omar AR, Subramani T, Yeap SK, Ho WY, Ismail NH, Ahmad S and Alitheen NB: Damnacanthal is a potent inducer of apoptosis with anti-cancer activity by stimulating p53 and p21 genes in MCF-7 breast cancer cells. Oncol Lett 7: 1479-1484, 2014.

17. Cancer Registry Unit NCIT: Cancer in Thailand Vol. VIII. New Thammada Press (Thailand) Co., Ltd., 2015.

18. Potter JD, Slattery ML, Bostick RM and Gapstur SM: Colon cancer: A review of the epidemiology. Epidemiol Rev 15: 499-545, 1993.

19. Chan-Blanco Y, Vaillant F, Pérez A, Reynes R, Brillouet JM and Brat P: The noni fruit (Morinda citrifolia L.): A review of agricultural research, nutritional and therapeutic properties. J Food Comp Analy 19: 645-654, 2006.

20. Ishizawa J, Kojima K, Hail $\mathrm{N}$ Jr, Tabe $\mathrm{Y}$ and Andreeff $\mathrm{M}$ : Expression, function, and targeting of the nuclear exporter chromosome region maintenance 1 (CRM1) protein. Pharmacol Ther 153: 25-35, 2015.

21. Yao Y, Dong Y, Lin F, Zhao H, Shen Z, Chen P, Sun YJ, Tang LN and Zheng SE: The expression of CRM1 is associated with prognosis in human osteosarcoma. Oncol Rep 21: 229-235, 2009.

22. Noske A, Weichert W, Niesporek S, Röske A, Buckendahl AC, Koch I, Sehouli J, Dietel M and Denkert C: Expression of the nuclear export protein chromosomal region maintenance/exportin $1 / \mathrm{Xpo1}$ is a prognostic factor in human ovarian cancer. Cancer 112: 1733-1743, 2008.

23. Huang WY, Yue L, Qiu WS, Wang LW, Zhou XH and Sun YJ: Prognostic value of CRM1 in pancreas cancer. Clin Invest Med 32: E315, 2009.

24. Shen A, Wang Y, Zhao Y, Zou L, Sun L and Cheng C: Expression of CRM1 in human gliomas and its significance in p27 expression and clinical prognosis. Neurosurgery 65: 153-160, 2009

25. van der Watt PJ, Maske CP, Hendricks DT, Parker MI, Denny L, Govender D, Birrer MJ and Leaner VD: The Karyopherin proteins, Crm1 and Karyopherin beta1, are overexpressed in cervical cancer and are critical for cancer cell survival and proliferation. Int J Cancer 124: 1829-1840, 2009.

26. Inoue $\mathrm{H}$, Kauffman $\mathrm{M}$, Shacham $\mathrm{S}$, Landesman $\mathrm{Y}$, Yang $\mathrm{J}$, Evans CP and Weiss RH: CRM1 blockade by selective inhibitors of nuclear export attenuates kidney cancer growth. J Urol 189: 2317-2326, 2013.

\footnotetext{
This work is licensed under a Creative Commons Attribution-NonCommercial-NoDerivatives 4.0 International (CC BY-NC-ND 4.0) License.
} 